\title{
The Glycosyltransferases of LPS Core: A Review of Four Heptosyltransferase Enzymes in Context
}

\author{
Joy M. Cote and Erika A. Taylor* \\ Department of Chemistry, Wesleyan University, Middletown, CT 06459, USA; jcote@wesleyan.edu \\ * Correspondence: eataylor@wesleyan.edu; Tel.: +1-860-685-2739; Fax: +1-860-685-2211
}

Received: 29 September 2017; Accepted: 24 October 2017 ; Published: 27 October 2017

\begin{abstract}
Bacterial antibiotic resistance is a rapidly expanding problem in the world today. Functionalization of the outer membrane of Gram-negative bacteria provides protection from extracellular antimicrobials, and serves as an innate resistance mechanism. Lipopolysaccharides (LPS) are a major cell-surface component of Gram-negative bacteria that contribute to protecting the bacterium from extracellular threats. LPS is biosynthesized by the sequential addition of sugar moieties by a number of glycosyltransferases (GTs). Heptosyltransferases catalyze the addition of multiple heptose sugars to form the core region of LPS; there are at most four heptosyltransferases found in all Gram-negative bacteria. The most studied of the four is HepI. Cells deficient in HepI display a truncated LPS on their cell surface, causing them to be more susceptible to hydrophobic antibiotics. HepI-IV are all structurally similar members of the GT-B structural family, a class of enzymes that have been found to be highly dynamic. Understanding conformational changes of heptosyltransferases are important to efficiently inhibiting them, but also contributing to the understanding of all GT-B enzymes. Finding new and smarter methods to inhibit bacterial growth is crucial, and the Heptosyltransferases may provide an important model for how to inhibit many GT-B enzymes.
\end{abstract}

Keywords: LPS; lipopolysaccharide; heptosyltransferase; protein dynamics; glycosyltransferase; GT-B; inhibitor design

\section{Introduction}

Well before the discovery of penicillin, bacteria have been evolving to resist natural antibiotics and other extracellular threats [1]; however, advances in medical techniques and over use of antibiotics has lead to an exponential increase in resistance. The resulting bacteria that are resistant to multiple antimicrobial agents are regarded as one of the biggest threats to global health, food security and development by both the World Health Organization (WHO) and Centers for Disease Control and Prevention (CDC) $[2,3]$. Gram-negative bacteria are of particular concern because their peptidoglycan is protected behind the bacterium's outer membrane (OM). Furthermore, the physical properties of the OM enhance bacterial survival in diverse environments and while also limiting the uptake of many drugs [4].

The overall organization of the OM is largely conserved, despite some variability between different Gram-negative bacteria. Typically, the OM contains a phospholipid bilayer with the extracellular leaflet being composed of a mixture of lipopolysaccharides (LPS), lipoproteins, and oligosaccharides [5-7]. LPS are the primary component of the OM in most species of Gram-negative bacteria and have been shown to play an important role in cell motility, intestinal colonization, bacterial biofilm formation, and antibiotic resistance [8,9]. This makes understanding the role of LPS in host-pathogen interactions an area of great interest, especially in the development of therapeutic agents for the treatment of gram-negative bacterial infections [10].

The LPS is composed of three main sections: a hydrophobic lipid A anchored to the membrane, a core oligosaccharide containing octulose and heptose sugar moieties, and a repeating $\mathrm{O}$-antigen 
region containing a diversity of sugars that are unique to bacterial cell surfaces (including pentoses, deoxy-hexoses, lactyl functionalized hexoses, heptoses and nonuloses) [11-13]; these components vary slightly between different bacteria $[9,14]$. The core oligosaccharide is further divided into the inner and outer core; the inner core is highly conserved and proximal to lipid A whereas the outer core is more variable. It is possible that the evolutionarily preserved structure of the inner core may be crucial for establishing the barrier function of the OM [15]. As can been seen in a schematic of E. coli OM biosynthesis, the complex synthesis and transportation of LPS involves many proteins (Figure 1) [7,16,17]. Sequential glycosyl transfer from nucleotide sugar precursors by membrane associated (or proximal) glycosyltransferases (GT) on the cytoplasmic face of the plasma membrane form the inner and outer core which is then transported to the periplasm where the fully formed O-antigen repeat is attached and the full LPS is exported to the outer leaflet $[7,9,17]$. Mutations in the biosynthesis of LPS are often lethal to bacteria, with the minimalistic structure required for secretion of LPS to the outer membrane being $\mathrm{Kdo}_{2}$-lipid A (lipid A with two 3-deoxy-D-manno-octo-2-ulosonic acid (Kdo) sugar moieties attached) $[9,18,19]$. Truncation of the LPS by mutations to the inner core display a deep-rough phenotype and exhibit hypersensitivity to hydrophobic antibiotics and detergents $[4,20,21]$.

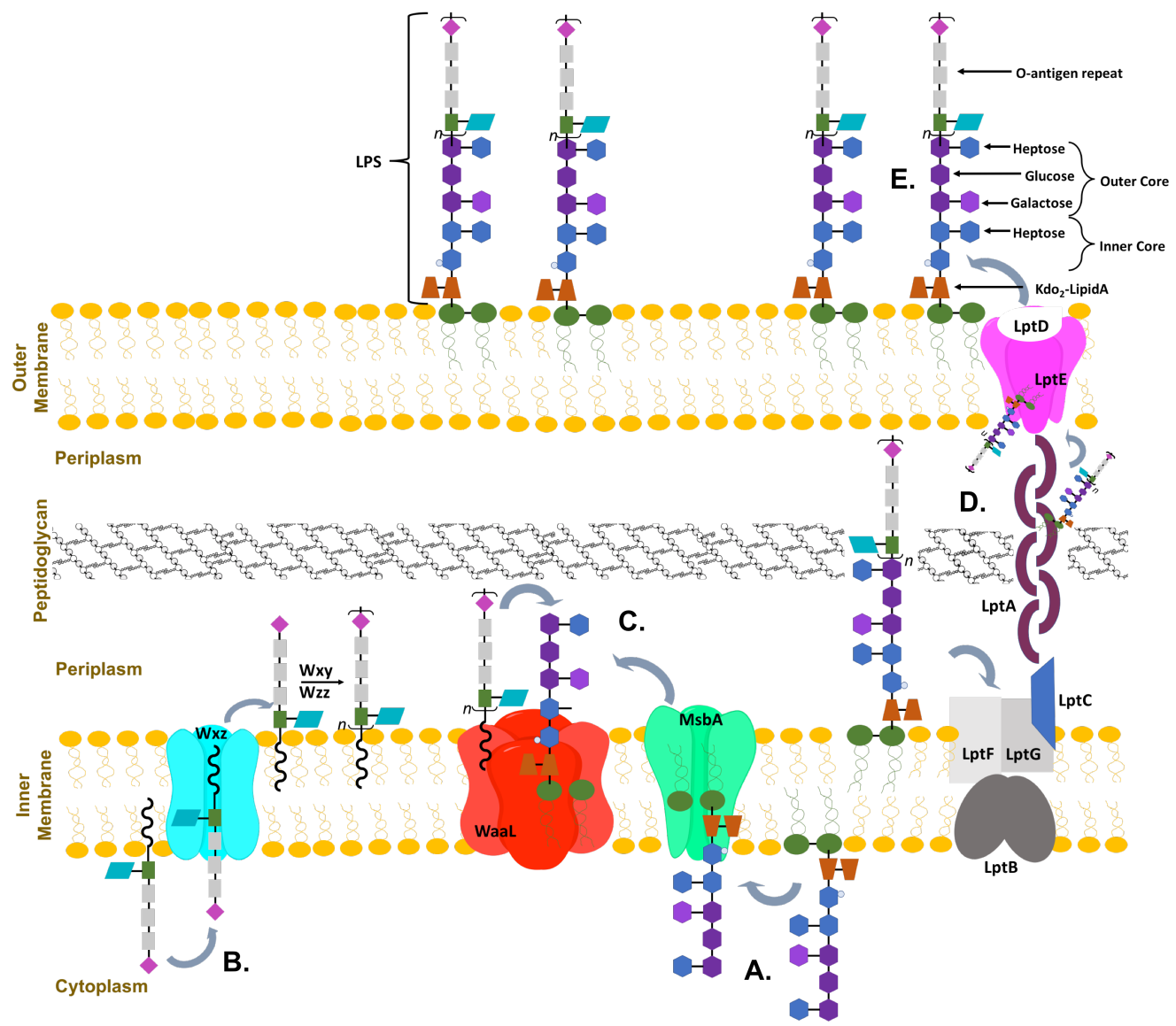

Figure 1. Representative organization of Gram-negative bacterium from Escherichia coli membrane. (A) demonstrates the sequential addition of inner core sugars to $\mathrm{Kdo}_{2}$-lipid A anchored into the inner membrane; (B) Represents the formation of the O-antigen repeat also formed in the inner membrane; (C) Once both are complete, they are flipped into the periplasm and the O-antigen repeats are attached to the top of the core; (D) The whole lipopolysaccharides (LPS) is then transported across the periplasm and peptidoglycan layer; (E) finally embedding into the outer membrane. 


\section{Glycosyltransferases}

Glycoslytransferases (GTs) are enzymes that catalyze the addition of various saccharides onto other biomolecules. GTs encompass a large group of enzymes that have similar structural scaffolds, but have evolved to utilize a vast diversity of substrates. Often, GTs act sequentially in order to build a complex polymer-the product of one GT will then be the acceptor substrate for the following GT. Many cellular functions such as: energy storage, cell wall structure, cell-cell interactions, signaling, host-pathogen, and protein glycosylation are dependent upon complex carbohydrates and polysaccharides. Due to this, biosynthesis of these chemically diverse oligosaccharides and polysaccharides require the use of multiple GTs [22-25].

\subsection{Glycosyltransferase Structural Folds}

Presently, there are over 300,000 known and putative GTs according to CAZY.org (Carbohydrate-Active enZYmes Database) and the number is ever growing [26]. Although GTs have diverse sequences, they can be characterized into three structural classes: GT-A, GT-B, and GT-C (Figure 2). Despite their differences, GTs catalyze the formation of a glycosidic bond, where a high-energy sugar nucleotide donates a monosaccharide to an acceptor molecule [27]. This acceptor can be a variety of molecules, such as oligosaccharides, monosaccharides, proteins, lipids, and others [23].

\subsubsection{GT-A Structural Fold}

SpsA from (Bacillus subtilis) was the first enzyme to be crystallized and characterized with a GT-A fold [28]. This structural family is characterized by two tightly packed domains, comprised of two $\beta \alpha \beta$ Rossman-like folds, that are closely associated to form a continuous central $\beta$-sheet (Figure $2 \mathrm{~A}$ ). The close proximity of the folds lead many to describe the GT-A fold as a single domain, however there are distinct binding sites for the two substrates [25]. A short N-terminal domain binds the donor substrate and C-terminal domain is an open groove that binds an acceptor substrate.

GT-A enzymes typically contain two Asp residues separated by a non-conserved amino acid (DXD motif), that is located on a loop connecting the central $\beta$-sheet to an additional smaller $\beta$-sheet. A divalent cation interacts with one or both of the Asp residues and is essential for stabilization of the pyrophosphate group of the donor substrate. Typically absence of the cation renders the enzyme inactive, however there are a small number of GT-A enzymes where a DXD motif and cation are not required [29]. Additionally, in order for both substrates to bind and for catalysis to occur a conformational change is required. Specifically, the loops adjacent to the active site, often adopt a variety of conformations to assist in binding the substrate and performing chemistry [30].

\subsubsection{GT-B Structural Fold}

Similar to the GT-A structural class, the GT-B protein contains two $\beta \alpha \beta$ Rossman-like domains. Unlike GT-A proteins, in the GT-B structural class the two domains are connected by a linker region with a deep cleft containing the active site separating the two domains (Figure 2B). Donor substrate binds to the $\mathrm{C}$-terminal domain, while the $\mathrm{N}$-terminal domain binds the acceptor substrates. A large domain movement is required for catalysis to occur in many GT-B enzymes [25,31-34]. There are no divalent metal ions or DXD motif in GT-B enzymes, and it is believed that the pyrophosphate is stabilized by charged and polar residues as well as the natural dipole of the $\alpha$-helices located in the donor substrate binding site [24].

A DNA-modifying $\beta$-glucosyltransferase was the first GT-B to be structurally characterized, and was shown to have both an open and closed conformation. The closed conformation is at least in part caused by binding of donor substrate uridine diphosphate glucose (UDP-glucose) [32]. Nonetheless, donor substrate binding does not alway induce a conformational change in GT-B enzymes. For instance, heptosyltransferase I (HepI), which has been crystallized with and without an analog to its donor substrate, ADP-L-(glycero)-D-(manno)-heptose (ADPH), shows no donor substrate induced closure [31]. 
Some GT-B enzymes are closed with acceptor bound thus, the order or ligand state required for closure does not seem to be universal across the family.

A.

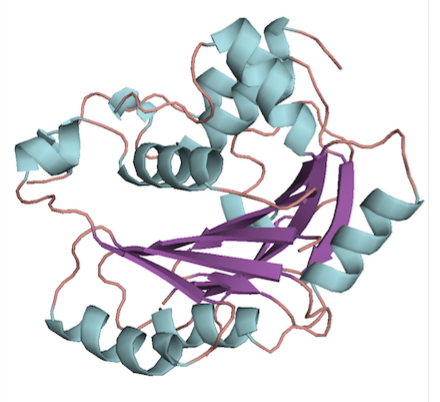

B.

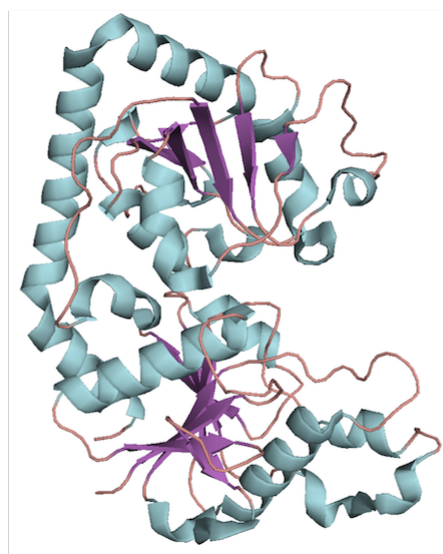

C.

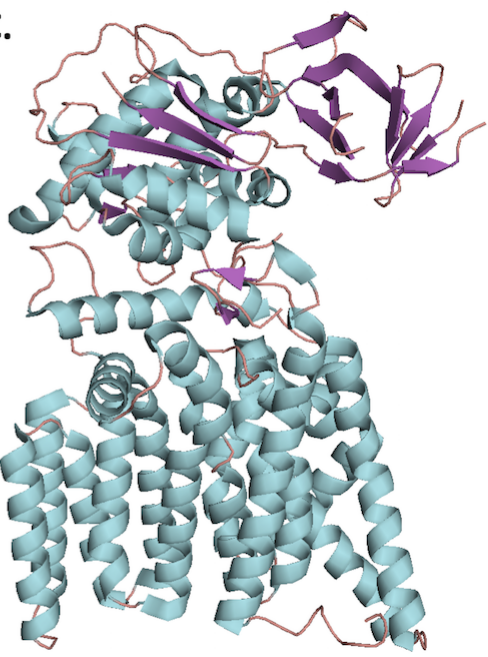

Figure 2. Representative folds of the first glycosyltransferase (GT) enzymes crystallized in each structural family: loops, $\alpha$-helices, and $\beta$-sheets are colored salmon, cyan, and purple respectively. (A) GT-A fold represented by SpsA from Bacillus subtilus, PDB: 1QGQ; (B) GT-B fold represented by bacteriophage T4 $\beta$-glucosyltransferas, PDB: 1JG7; (C) GT-C fold represented by PglB from Campylobacter lari, PDB: 3RCE.

\subsubsection{GT-C Structural Fold}

Until recently, the third structural fold (GT-C) was only predicted on the bases of sequence analysis [35]. In 2011, the first GT-C structure was published for a bacterial oligosaccharyltransferase from Campylobacter lari, comprised of 2 domains: a 13 transmembrane domain and a periplasmic domain containing a mix of $\alpha / \beta$ folds [36]. Both GT-A and GT-C enzymes have a DXD motif, however the location of the DXD tripeptide in GT-C family is at the carboxy-terminal end of the first transmembrane helix. A small patch of hydrophobic amino acids following the helix is common. Although this arrangement is similar to that of the DXD signiture in GT-A structural fold, there is no conservation of sequence between these two regions [24,36].

\subsubsection{Catalytic Mechanisms}

Regardless of the structural fold, glycosyltransferases catalyze the transfer of a glycosyl group with either inversion or retention of the stereoconfiguration at the anomeric carbon. Both GT-A and GT-B families have been found to have inverting and retaining enzymes, however all GT-C enzymes are predicted to utilize an inverting mechanism. While literature often states that inverting GTs follow a $\mathrm{S}_{\mathrm{N}}$ 2-like mechanism, implying an uncharged transition state, it is generally accepted that the reaction has an oxocarbenium ion like transition state which is more correctly defined as a partially associated $S_{N} 1$-like mechanism (Figure 3B) [37,38]. Unlike inverting GTs, there are multiple mechanism for retaining enzymes. Initially, it was thought that all retaining enzymes proceed via a double displacement mechanism with formation of a covalent glycosyl-enzyme intermediate (Figure 3C); nevertheless, only a small percentage of GTs contain a putative nucleophilic residue that is properly located in the active site to facilitate such a mechanism $[25,39,40]$. There is little direct evidence for a double displacement mechanism in the literature, however Soya et. al. was able to observe glycosyl-enzyme intermediates by mass spectrometry [41]. Further experimental and computational work has shown that a front face or $\mathrm{S}_{\mathrm{N}} \mathrm{i}$ (substitution nucleophilic internal-like) mechanism is likely the primary pathway utilized $[25,40,42,43]$. While there is more support for an $S_{N} i$ mechanism, it is 
generally accepted that there are two classes of retaining GTs, that are classified based on the presence or absence of a nucleophile in the active site.

A.

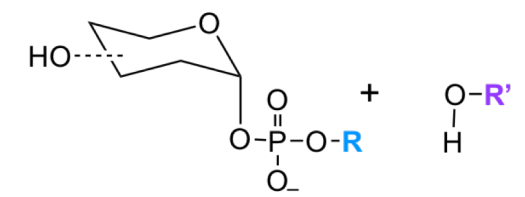

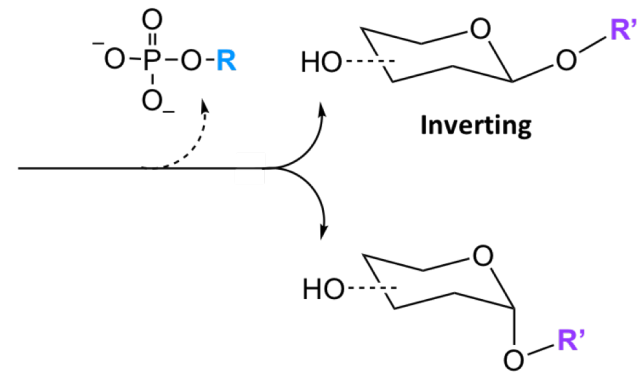

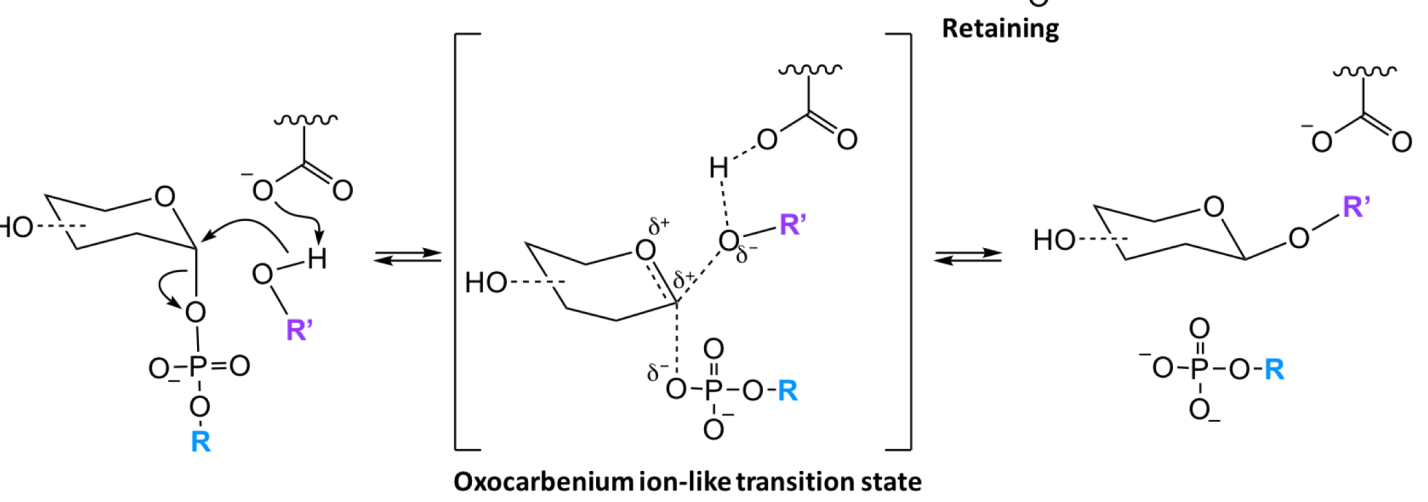

c.

B.

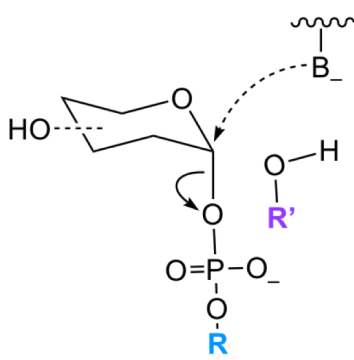

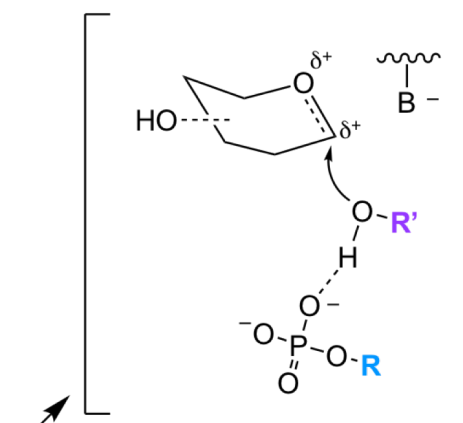

Short-lived oxocarbenium ion-like species<smiles>C1CCCCC1</smiles><smiles>[R]OCC(CCC)(CCCC)OCCC</smiles><smiles>[R]OP(=O)(O)OC</smiles><smiles>[R]O[C@H]1CC[C@@H](O)CO1</smiles>

Covalent glycosyl-enzyme species

Figure 3. Proposed catalytic mechanism of GT enzymes. (A) The transfer of a sugar moiety is performed with either inversion or retention of the anomeric carbon in respect to the sugar donor substrate; (B) Schematic of $\mathrm{S}_{\mathrm{N}} 1$-like mechanism for inverting GTs, where a single oxocarbenium ion-like transition state is formed; (C) There are currently two mechanisms for retaining GTs enzymes either through the formation of a short-lived oxocarbenium ion-like species or a covalent glycosyl-enzyme species. 


\section{Core Heptosyltransferase Enzymes}

Many GTs have been extensively studied due to their biological and medical importance. Notable of these enzymes are the heptosyltransferases that are involved in the biosythesis of the LPS inner core (and in some bacteria outer core). Heptosytransferases catalyze the sequential addition of heptose moieties onto $\mathrm{Kdo}_{2}$-lipid A (Figure 4) and are characterized as GT-B enzymes inverting reaction mechanism [44]. As mentioned earlier, in all Gram-negative bacteria, LPS is one of the major extracellular polymeric substances protecting the cell (a schematic of which is shown in Figure 1). For many bacteria the overall structure of LPS is highly conserved. However, as one moves away from the membrane the structure variability between bacterial species increases. Thus, the inner core of LPS has low variability where the outer core varies more between bacteria. Additionally, it has been shown that the less conserved regions are not required for bacterial viability [45]. In fact, the minimal structure required for bacterial survival is $\mathrm{Kdo}_{2}$-lipid A - the acceptor substrate for HepI $[9,18,19]$. Truncation of the LPS increases the bacteria sensitivity to hydrophobic antibiotics and detergents, making the heptosyltransferases, especially HepI, novel drug targets $[4,20,21]$.

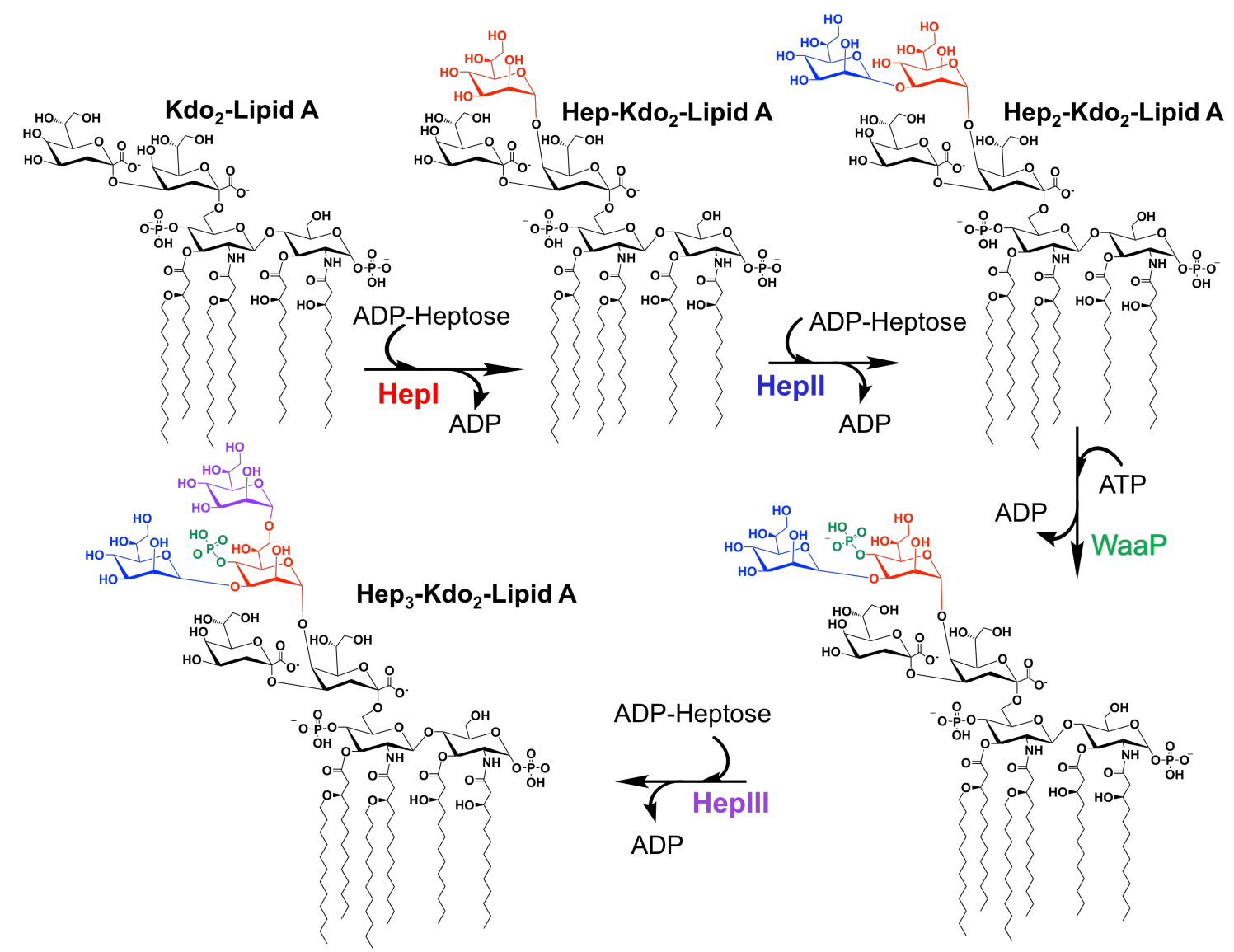

Figure 4. The sequential addition of three heptose moieties from ADPH catalyzed by Heptosytransferase I, II, and III (HepI, II, and III, respectively). Each moiety is color coded to match the enzyme that catalyzed the addition (red, blue, purple for HepI, II, and III, respectively). Prior to addition of the third heptose, WaaP phosphorylates the first heptose [46].

\subsection{Multiple Sequence Alignment (MSA) of Heptosyltransferase Enzymes}

Gram-negative bacteria have up to four heptosyltransferases; HepI and HepII are always present and catalyze the addition of the first two sugars of the inner core, whereas HepIII and HepIV are found only in some species (Figure 4). As a result HepI and HepII have been studied in many systems. To date, there has been little work on HepIII and even less on HepIV, despite both having been identified 
or suggested in Vibrio cholerae, Escherichia coli, Yersinia pestis, and Klebsiella pneumoniae. HepIII adds the third heptose to the inner core and HepIV adds a heptose moiety onto a glucose or galactose located within the outer core (Figure 1) [47,48]. A multiple seuqence alignment (MSA) of HepI-IV from Vibrio cholerae, Escherichia coli, Yersinia pestis, and Klebsiella pneumoniae shows the variability of sequence conservation among the heptosyltransferases (Figure 5). The average similarity for all 16 heptosyltransferases is about $30 \%$, which is consistent to the percent similarity for the HepI-IV enzymes from the same organism. By comparing each homolog to E. coli, it can be concluded that HepI and HepII are highly conserved with percent similarities as high as $86 \%$. HepIII and HepIV homologues have less then $46 \%$ similarity. It is perhaps unsurprising that each of the heptosyltransferases have the highest sequence similarity to their homologs rather than to the paralogs within an organism. HepIV are more divergent than HepI, most likely because the core region of LPS only varies only slightly, thus a HepI enzyme from E. coli and $V$. cholerae will bind more similar acceptor substrates than the corresponding HepIV enzymes [45].

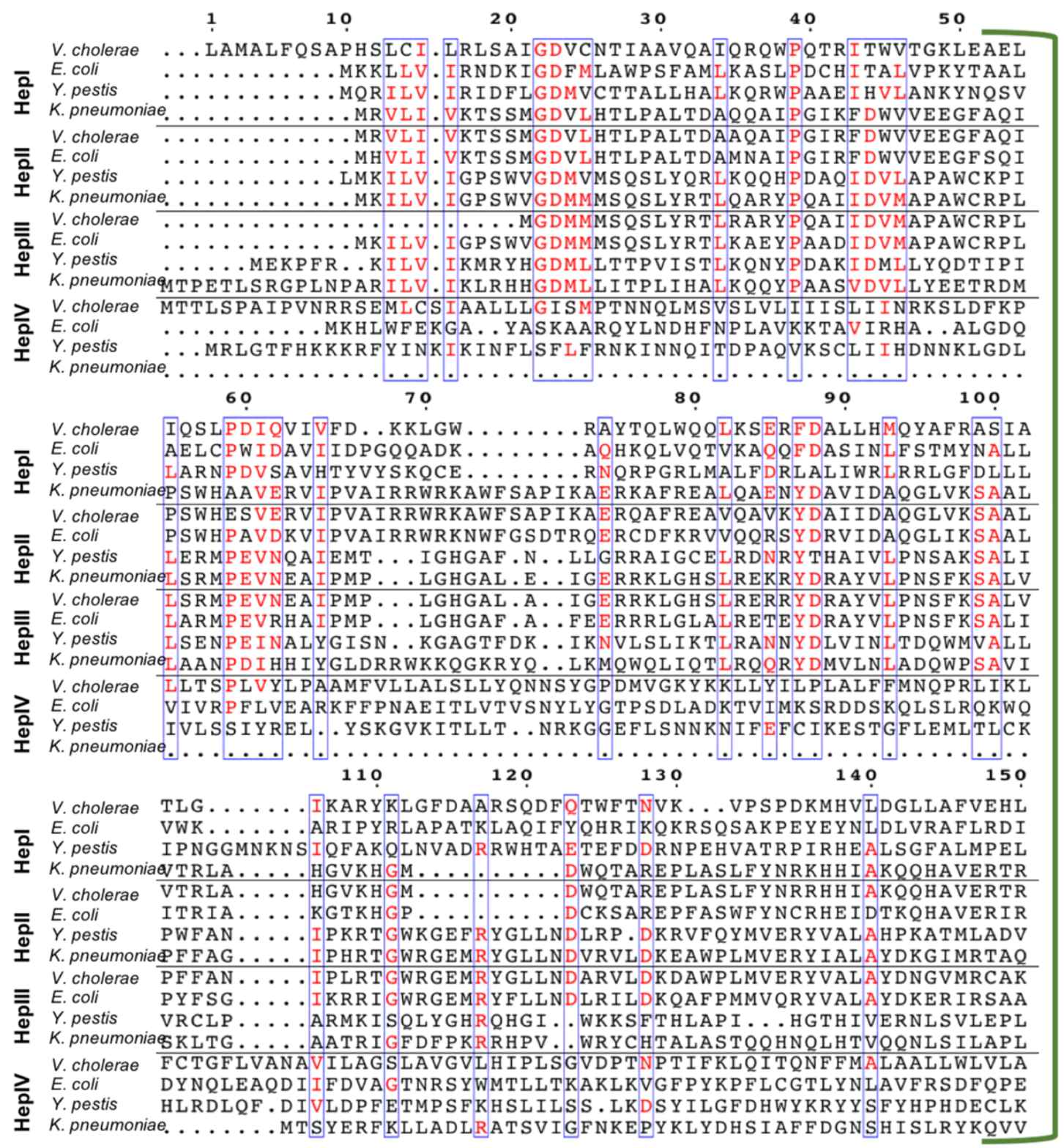

Figure 5. Cont. 


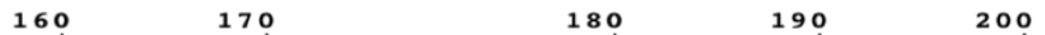

V. cholerae GIRDIEPKWSITCQPDDLTWAEAQ.. . . . FQPEQPRLVVVPGASKAYKNWTAEGYA

Y. pestis GOPI IEPNAPYLTFPAEOLAAOR K K AEOLDIGPDKAWLFVHAGSGGSANNLSLEOYC

K. pneumonia GRVDIE . TLKLHVYPEPOLOAKWOADL ..... GGKDRPRVGLF I SNKSAORRWSWDKWR

$\overline{\bar{a}}$ E. coli ELFAKSLGYAKPOTOGDYAIARHFLOHE . . . ASAAAPYLVFLHATTRDDKHWPETRWO QLFAKSLGYDKPESYGDYAIAORFLNQL.... PADAGQYLVFLHATTRDNKHWPESHWV K. pneumoniąL PQPLLWPQLQVS E GEKSYTCNQFS. L . . S SERPMIGFCPGAEF GPAKRWPHYHYA V. cholerae DLPOPLLWPQLQVNEGEKSOACSAFN. L . . SNDRPIVGFCPGAEFGPAKRWPHYHYA

E. coli

응 pestis DLPOPLLWPOLOVRDEEIAETTASFN. L . . T TDNRPI IGFCPGAEFGPAKRWPHYHYA GITDFYTDTTMSYAEDCWKKMRRELD. A . . . LGVKDHYVVIQPTARQIFKCWDNDKFS K. pneumoniagL OLNEAPARMGYSEADWAASRALLP. E. . . D DFREHYIVIOPTSRWFFKCWREDRMS V. cholerae FOHOGWKRWG Y SVLVVAASYS I L F LVL . . . . GRTGYVAL I VGLGVWLFF SLGNRORLT E. coli VECMLDMLKILGHNPSYPLDFAYPDNRQICDHAAPYIVYFSGASQLRKILTKPEMRAV Y.pestis EHMSTRAIEILKHIYGEG.KFSTNYDLHLPVDVEDKIKEFIGDTRI. VIINPLGAKKI

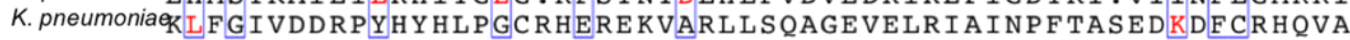

$$
210
$$

$$
220
$$

230

240

250

V. cholerae AVIEHAQQQGWQVILA. GSPAQVERDLAAQVEQALAHPVLNLVGKST. LQQMLALLAK 즐. Eoli I. pestis QLALKLNAQA.ELLIF.HDPAEQPSEQQLAGLTARC...... LSTPSTDDLMAAMSQ ELVTGVMDEHKOVVLT. AGPGEEEKAAOLOSLLAEOGVLAALYAKNDGLVDFTRSLAC

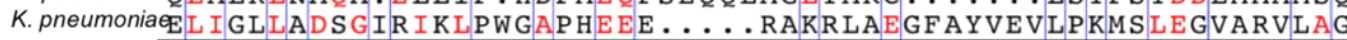
V. cholerae ELLDLLADSGVHIKLPWGAPHEEA ......RAKRLAEGREYVEVLPRMSLEOVAQVLAG

$\overline{\overline{0}}$ E coli

ํㅜ Y.pestis OL TELVOPTGLK IKL PWGAEHEHO..... RALRLAEHF PHVEVLPKLSLOOVAEVLAG

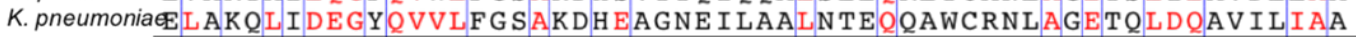

은 Y. pestis ALAKKLI DDGYO IALFG A KDNEAGKE I IAALS SEOOAWCRNLAGETOLEOAV I I IAA KVIVAL 作L INALAEGYAVVLT.SGPDAREKKMVDTIIAGCPOARLHSLAGOLTLROLAAVIDH V. cholerae LVVLGALAFAALIFI PNKATDR IVOGVDEIKVCMAASATDAADACNSSMGORSAFVVE $\geqq$ E. coli IEQTIQQQPNVKHVFLEGKNEFEKGEYLQDLADNGSLTIQ. . . PCLPLDDLVTFIAK 은 Y.pestis CRLTFEQ. . I KVIYQEVKTHFENYRI IFTGLPQDLLT I P I LE IETLPFDEF I Y TVAL I K. pneumonia TLVERLHALPYRVCIVMVGRSEKIRQLGLDMAL ........ I I A S TINSAVEVIRS

$\begin{array}{llllll}260 & 270 & 280 & 290 & 300 & 30\end{array}$

V. cholerae ...ADLVIAPDTGPAHMANAMHTPIIGLYAHHNERTGPYHYRHYVVSAYQEALLAET

*

I Y.pestis $\ldots$ LDLVISADSAPVHIGSALQI PVVALFESRPEK.... . YLRWYPLGVRHVLVHAGP K. pneumoniae $\cdots$ KFVVSVDTGLSHLTAALDR N I TVYGPT DPGLI GGYGKNOMVCRAPRENLI..N V. cholerae ...ARAVVSVDTGLSHLTAALDKPNFTLYGPTDPGLIGGYGKNOHIVRPENSAST. . G

$\overline{\overline{0}}$ E.coli $\quad \ldots$ AKAVVSVDTGLSHLTAALDRPNITLFGPTDPGLIGGYGKNQIAVISEQKKMD . . S

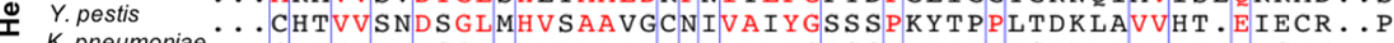
K. pneumoniae....CKAIVTNDSGLMHVAAALNRPLVALYGPS SP DFT P PLSHKARVIRL. ITGYH . . K CKAVVTNDSGLMHVAAAIDRPIVAIYGPSSPDFT PPISHKARVTRI.TTGYH.”K .. CSAVVSNDSGLMHVAAALNKPLVALYGPSSPDFTPPLSEKATVIRL. ITGYH . . K K. A. A L I GVD SAPGH I AAAVKT PVI SLF GAT DHVFWRPWTEN I IQFWAGNYQKM . P ....ARLF I GVD SVPMHMAAA L GT P L A LF GPSKLTFWR PWOAKGEVIWAGDFGPL . . P $\geq$ E. coli $\ldots$ AARL IKESP I L GHGAGG FYYENKEVDYKVNNPHNQYLLET I QSGVI GLF LF LAWV

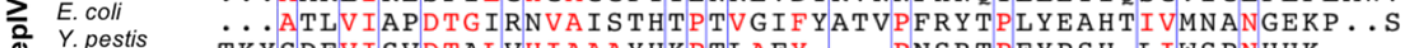
TKYSDFVISVDTALVHIAAAYHKPTLAFY....PNSRTPEYPSH.LIWSPNHHK... ...CDLVITPDTS IVH I ARAF D PMVAVYNKRKLKNTGLPGYH I WAPGY DKAKQIVCE

$$
320 \quad 330 \quad 340 \quad 350
$$

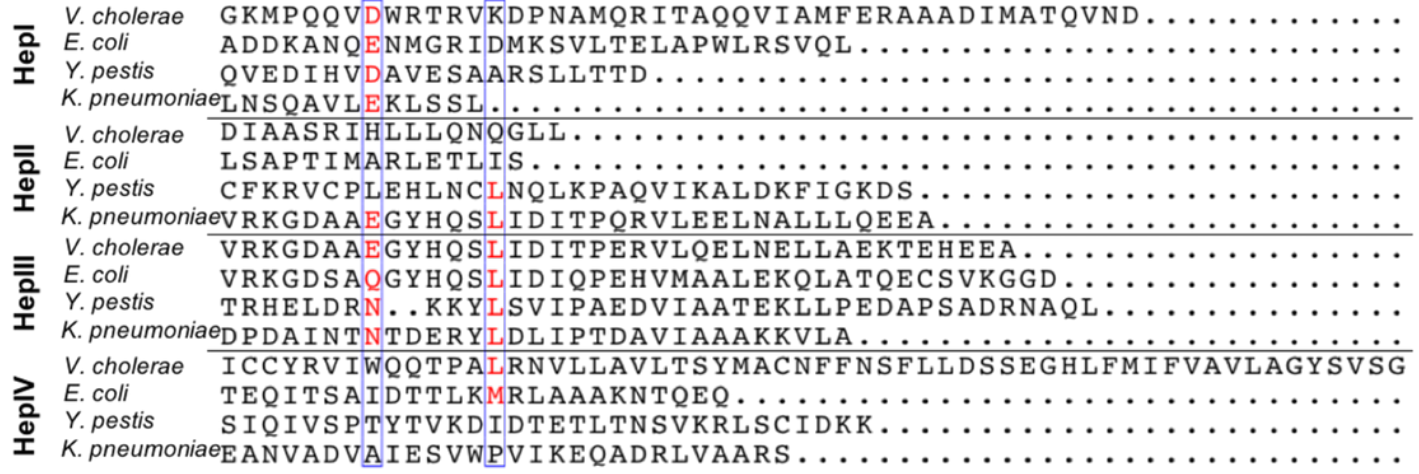

Figure 5. Muliple sequence alignment of HepI-HepIV from Vibrio cholerae, Escherichia coli, Yersinia pestis, and Klebsiella pneumoniae (domains for HepI E. coli HepI are annotated), using ClustalW 2.0 (https:/ / www.ebi.ac.uk/Tools/msa/clustalw2/) alignment program and Espript 3.0 (ESPript-http:/ / espript.ibcp.fr) $[49,50]$. 
Although HepI-IV are variable in their sequence, the C-terminus has the most conservation followed by the N-terminus, while the linker is highly variable, and the overall structure of heptosyltrasferases are homologous (Figure 6). In E. coli HepI and HepII have been crystallized, and the structure of HepIII has been computationally predicted (Figure 6A-C) [51]. A computational model of E. coli HepIV was created using the I-Tasser protein structure prediction program (the resulting structure is shown in Figure 6D) and it appears similar to HepI and HepII crystal structure [52-54]. All are GT-B proteins with the the typical $\beta \alpha \beta$ Rossman-like domains attached by a linker. The C-terminal domain for all, binds ADPH (the donor substrate) and look nearly identical, whereas the $\mathrm{N}$-terminal domain varies slightly, likely due to their variation in acceptor substrates $[31,51]$.

A.

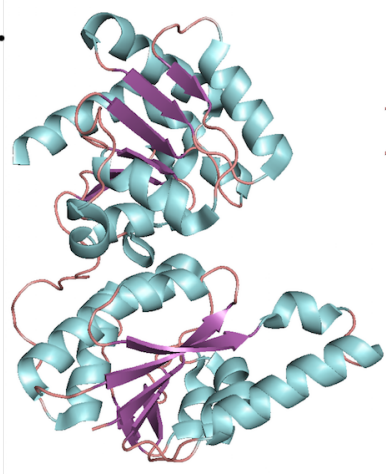

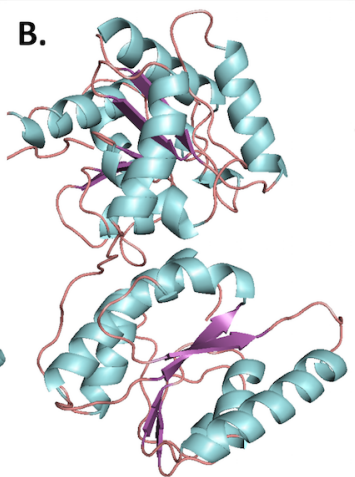
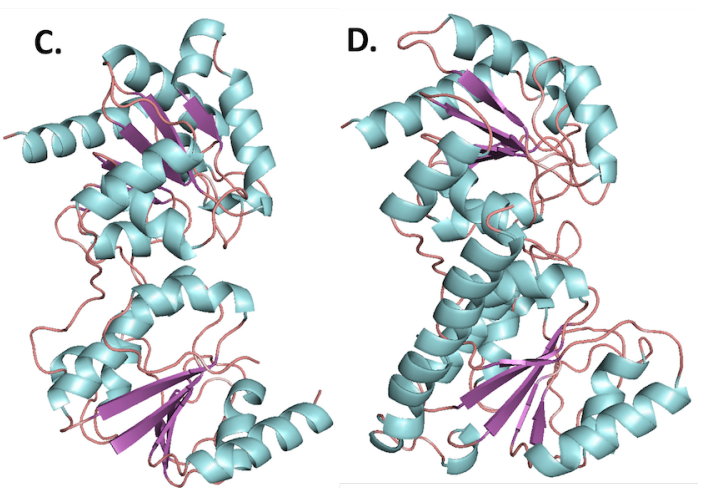

Figure 6. Structures of Heptosyltransferases (loops, $\alpha$-helices, and $\beta$-sheets are colored salmon, cyan, and purple, respectively). (A) HepI from E. coli, PDB: 2H1H; (B) HepII from E. coli, PDB: 1PSW; (C) Computational model of HepIII from E. coli [51]; (D) Computational model of HepIV from E. coli.

To better compare the the structural variety of E. coli HepI-IV a sequence-based structural superposition was generated using HepI $(\mathrm{PDB}: 2 \mathrm{H} 1 \mathrm{H})$ as the reference structure, with the VMD multiseq program. An overlay showing the conserved residues in the HepI-IV structures are displayed in Figure 7 (the blue areas indicate highly conserved regions and the red depicts non-conserved regions). By looking at the global conservation of heptosyltransferases, the interior is more conserved, while the surface residues are highly variable. Additionally, it is evident that the C-terminus (binding domain of ADPH for all heptosyltransferase enzymes) is more conserved than the N-terminal domain. The proposed catalytic base D13 is present in all the heptosyltransferases, suggesting that the mechanism of action for all heptosyltransferases are similiar [31]. Other specific residues, like K192 and D261 (which were shown by mutagenesis studies in HepI to be important for chemistry), are completely conserved for all E. coli heptosyltransferases as well as all Vibrio cholerae, Escherichia coli, Yersinia pestis, and Klebsiella pneumoniae. It is clear that all of the heptosyltransferase enzymes are structurally similar and many important residues are conserved not only between $E$. coli heptosyltransferase enzymes, but also in multiple bacterial species. Bacterial evolution to differentiate the LPS structure enhancing survival in different niches likely governs the sequence variability of heptosyltransferases. 


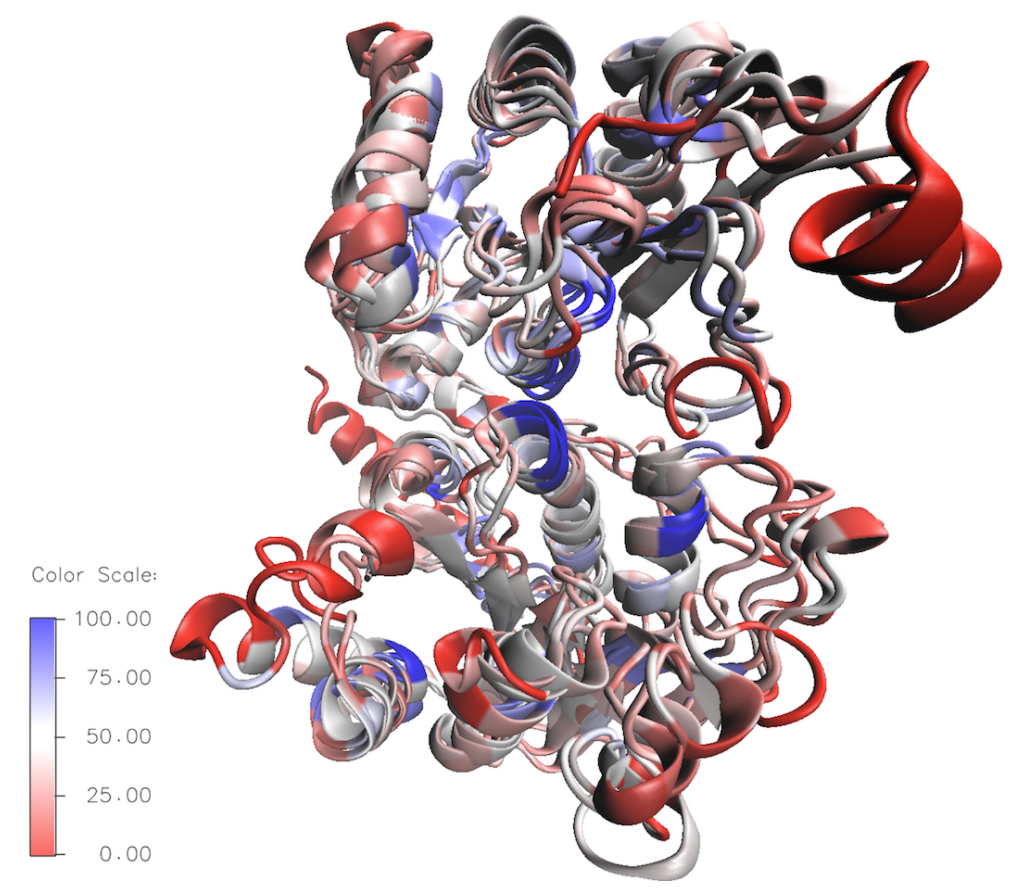

Figure 7. Overlay of Structurally aligned HepI-IV; residues are colored by sequence similarity [highly conserved (blue) non-conserved (red)].

\subsection{Heptosyltransferase I}

E. coli HepI, the most characterized heptosyltransferase, can reveal insights about the function of the other heptosyltransferase enzymes. The acceptor substrate of HepI, $\mathrm{Kdo}_{2}$-lipid $\mathrm{A}$, is the minimalistic structure required for LPS to be transported to the outer membrane. Mutations to waaC $(r f a C)$, the gene that codes for HepI, leads to a rough phenotype LPS and an increase in sensitivity to hydrophobic antibiotics including: erthromycin, ampicillin, and novobiocin [10]. Early work on HepI sought to use alternative donor substrates as ADPH was not commercially available. ADP-mannose, GDP-manose, ADP-glucose, UDP-glucose, and UDP-galactose were tested for HepI transferase activity, only ADP-mannose was a viable alternative substrate. ADP-mannose was characterized by Kadrmas et al. to have an apparent $V_{\max }$ of $3 \mu \mathrm{mol} / \mathrm{min} / \mathrm{mg}$ and a $K_{\mathrm{M}}$ of $1.47 \mathrm{mM}$. Kdo-lipid A (an analogue of $\mathrm{Kdo}_{2}$-lipid A with only one Kdo) was a poor mannose acceptor substrate; this was unexpected since the second Kdo moiety was not expected to influence activity since the first Kdo is the one being modified by HepI [55]. Later work using the native substrate ADPH showed that Kdo-lipid A was in fact a competent acceptor substrate with a $K_{\mathrm{M}}$ of $46 \mu \mathrm{M}$ [56]. Perhaps using two alternative substrates was the reason for the poor transferase activity, and in fact Kdo-lipid A may be sufficient for the continual formation of the inner core. Interestingly, the fatty acid chains were shown to not be important for catalysis, as has been demonstrated to be necessary in other LPS biosynthetic enzymes. The substrate analogue, $\mathrm{Kdo}_{2}$-lipid $\mathrm{IV}_{\mathrm{A}}$, although missing three fatty acid chains normally present in $\mathrm{Kdo}_{2}$-lipid A, gives a $K_{\mathrm{M}}$ of $4.7 \mu \mathrm{M}$ demonstrating that the removal of fatty acid chains does not impair chemistry. Furthermore, HepI has activity with the fully deacylated and O-deacylated $\mathrm{Kdo}_{2}$-lipid A (ODLA and FDLA respectively, Figure 8). Both were shown to be competent substrates; native substrate had a $K_{M}$ of $29 \mu \mathrm{M}$ where the analogues displayed a $K_{\mathrm{M}}$ of $1 \mu \mathrm{M}$ (ODLA) and $0.3 \mu \mathrm{M}$ (FDLA) [56]. Retrospectively, it is unsurprising that the fatty acid chains would be unimportant for catalytic efficiency since they are embedded into the inner membrane in vivo and therefore should not be accessible to influence binding. Taken together with the slightly better catalytic efficiency for deacylated $\mathrm{Kdo}_{2}$-lipid A analogues, these observations suggest that the tetrasaccharide portion of the substrate provides HepI with the primary binding interactions required for acceptor substrate recognition. 
A.

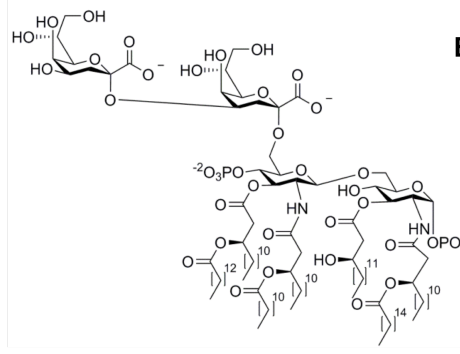

B.

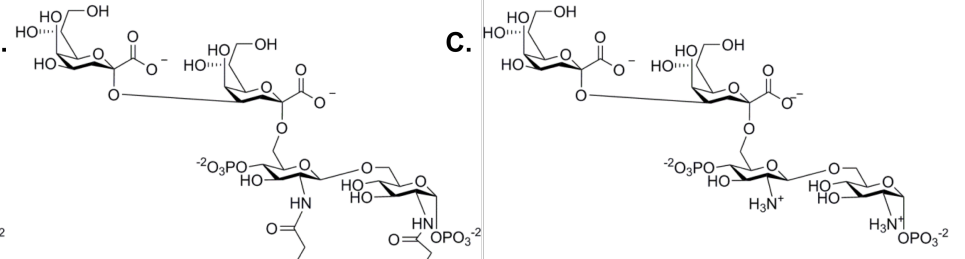

Figure 8. Strucutres of $\mathrm{Kdo}_{2}$-lipid A and analogues: (A) E. coli $\mathrm{Kdo}_{2}$-lipid A; (B) O-deacylated E. coli $\mathrm{Kdo}_{2}$-lipid A (ODLA) and (C) fully deacylated E. coli Kdo 2 -lipid A (FDLA).

\subsubsection{Crystal Structures of HepI}

As mentioned earlier, the structure of HepI has been previously determined. Three different structures are available in the PDB: $2 \mathrm{GT} 1,2 \mathrm{H} 1 \mathrm{H}$, and $2 \mathrm{H} 1 \mathrm{~F}$ corresponding to the Apo protein, HepI-ADP-2-deoxy-2-fluoro-heptose (ADPF) complex and HepI-ADP complex, respectively [31]. By comparing the three structures it seems that HepI does not undergo a domain rotation upon donor substrate binding like other GT-B's. However, as there is no crystal structure in complex with $\mathrm{Kdo}_{2}$-lipid A or any of its analogues, and it is, therefore, possible that HepI closure is induced by the acceptor substrate or by formation of the ternary complex, as has been shown by other GT-B's. ADPF is a non-cleavable analogue to ADPH with a fluorine replacing a hydroxyl group in the $2^{\prime}$-position. ADPF has been shown to be an inhibitor of HepI with an $\mathrm{IC}_{50}$ of $30 \mu \mathrm{M}$ [31]. Attempts to crystallize HepI with ADPH lead to co-crystallization with ADP, suggesting that HepI is capable of hydrolysis in the absence of an acceptor, a phenomenon that was observed with other glycoslytransferases [34,57]. Upon crystallization of HepI, Grizot et al. performed site-directed mutagenesis to test the importance of numerous residues on catalysis and binding of ADPH. D13A and D261A exhibit a 4688-fold and 2027-fold drop in specific activity, respectively and were suggested to be catalytic residues. K192A had a 926-fold reduction in activity and due to its location proximal to the anomeric carbon of ADPH which is where the deprotonated hydroxyl of $\mathrm{Kdo}_{2}$-lipid A attacks, and therefore may play an important role in binding or catalysis and binding [31].

\subsubsection{Inhibition of HepI}

One goal of understanding the heptosyltransferases is to learn how to effectively inhibit them, to date some work has been done to design inhibitors for HepI. Most inhibitors of GTs bind typically with low $\mu \mathrm{M}$ affinities, similar to $K_{\mathrm{M}}$ values of substrate. A structure-activity relationship (SAR) study was done by Moreau et. al. on a series of 2-aryl-5-methyl-4-(5-aryl-furan-2-yl-methylene)2,4-dihydro-pyrazol-3-one analogues (Figure 9A) [58]. In this work, computational docking and biochemical assays were used to assess binding. All compounds bound with low $\mu \mathrm{M} \mathrm{IC}_{50}$ 's and appeared to be preferentially bound close to acceptor site of $\mathrm{Kdo}_{2}$-lipid A, specifically near where Kdo should bind. Residues R120, H139, A140, R143, and I287 were identified as important for inhibitor binding in this analysis, suggesting the potential importance of these residues for $\mathrm{Kdo}_{2}$-lipid A binding. Further studies would need to be done however to test this hypothesis.

Additionally, Durka et al. published a library of synthesized multivalent glycosylated fullerene monomers and "balls" much larger than the proposed molecules previously discussed. Like the previous series, these compounds had inhibition constants in the low $\mu \mathrm{M}$ ranging from $7-47 \mu \mathrm{M}$, again on par $K_{\mathrm{M}}$ of substrates [59]. In 2016, the group published a second series of glycofullerenes slightly varying the fullerenes in an attempt to increase inhibition. The new fullerene compounds were competitive against $\mathrm{Kdo}_{2}$-lipid $\mathrm{A}$ and uncompetitive towards $\mathrm{ADPH}$, which was unexpected because the compounds were designed to mimic ADPH heptose moiety; similar to previously discussed work, the compounds showed low $\mu \mathrm{M} K_{i}$. From these findings, glycoclusters mimicking Kdo with $\mathrm{C}_{60}$ and 
other multivalent scaffolds were synthesized and $\mathrm{IC}_{50}$ were calculated. Interestingly, high nanomolar inhibition was observed for Kdo fullerenes attached to $\mathrm{C}_{60}$ scaffolds, a degree of inhibition never achieved for HepI and rarely for GTs [60].

A.<smiles>[R]c1cccc(-c2ccc(C3C(=O)N(c4cccc([R])c4)N=C3C)o2)c1</smiles>

B.

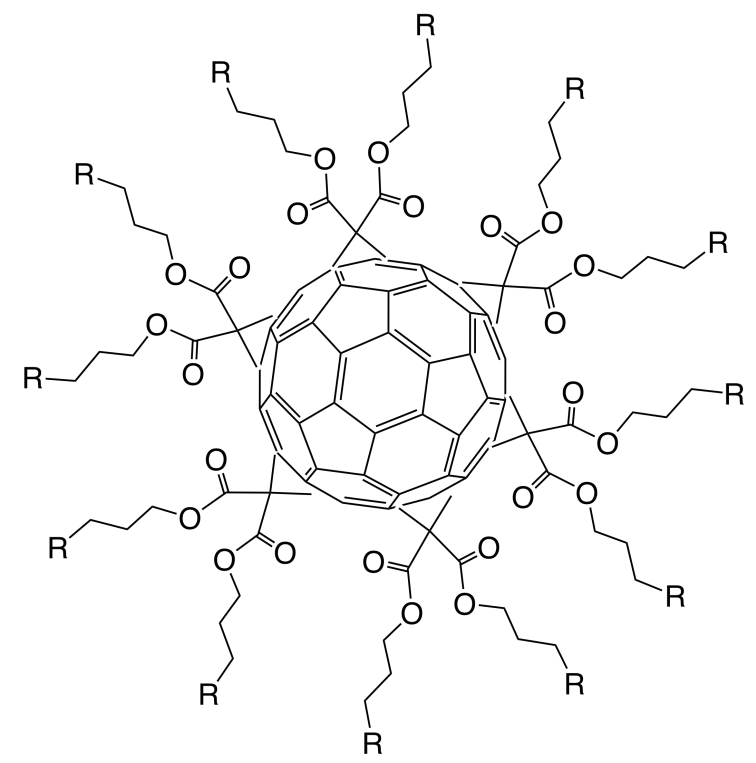

Figure 9. (A) Representative core structure of 2-aryl-5-methyl-4-(5-aryl-furan-2-yl-methylene)-2,4-dihydropyrazol-3-one analogues [58]; (B) Glycofullerene derivatives schematic [59].

\subsubsection{Investigations of HepI Protein Dynamics}

As mentioned earlier, a few GT-B glycosyltransferases have been shown to inter-convert between an "open" and "closed" structure [32-34]. Without a crystal structure of the ternary complex of HepI, it is unclear how/if HepI undergoes such an event. By looking at the crystal structure however, its is clear that the catalytic base (D13) is over $8 \AA$ away from the anomeric carbon of ADPH which is too far away for efficient nucleophilic attack by deprotonated $\mathrm{Kdo}_{2}$-lipid A [31]. Thus, it was hypothesized that HepI also undergoes a conformational change during the reaction. To assess protein dynamics, HepI steady state activity was tested in a variety of viscous buffers, specifically glycerol, ethylene glycol, and PEG 8000. Microviscogens; glycerol, and ethylene glycol, both had a strong impact on $k_{\mathrm{cat}}$ which could be explained by water reorganization being required for catalysis; this suggests that HepI conformational dynamics are partially rate-limiting [61].

Additionally, intrinsic tryptophan (Trp) fluorescence spectroscopy was employed to see if substrate binding induced changes in the protein fluorescence spectra [62-70]. HepI has 8 tryptophan residues, and by examination of a computational model of the closed structure of HepI, many of the Trp residues appear to become more buried in the protein, suggesting that upon substrate binding there may be a change in fluorescence spectrum (Figure 10A). Fluorescence spectra were obtained with and without substrates(Figure 10B). Consistent with crystal structures, no change was observed upon ADPH binding alone. ODLA binding resulted in a $6 \mathrm{~nm}$ blue shift, suggesting that ODLA binding induces conformational changes that lead to one or more the the Trp residues to becoming more buried in the protein [61]. 

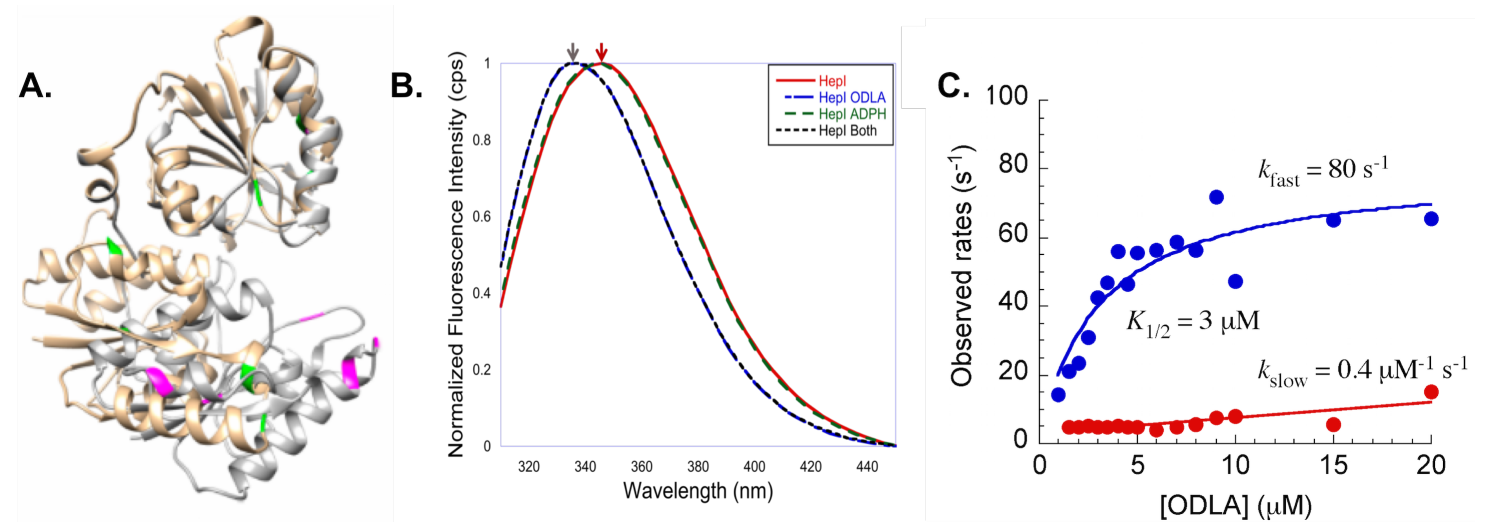

Figure 10. (A) HepI open structure (tan) and trypophan residues colored in green is superimposed with a structural model of closed HepI (gray) with tryptophans colored magenta; (B) Steady state intrinsic tryptophan emission spectra of HepI with and without substrates bound, blue shift is observed upon ODLA binding; (C) Pre-steady state kinetics of WT HepI titrated with ODLA (fast phase, blue; slow phase, red).

When stopped flow was used to monitor the kinetics of conformational changes in HepI, a concentration of ODLA dependent biphasic pre-steady state kinetics was observed. Two rates were observed, a fast rate which exhibits a hyperbolic dependence on ODLA concentration (saturates at $80 \mathrm{~s}^{-1}$ ), and a concentration independent slow rate of $\sim 5 \mathrm{~s}^{-1}$. A two step binding mechanism of ODLA was suggested (initial collision complex between of HepI and ODLA followed one or more conformational change(s) to form the HepI.ODLA complex). Additionally, a catalytically impaired mutant (D13A) of HepI was tested and yielded the same pre-steady state kinetics. This suggests that the ODLA induced change in HepI must occur prior to chemistry [61]. Subsequently, work investigated which Trp residue(s) play(s) a role in the observed blue shift so as to better understand conformational change(s) that occur [71]. In this work, most of the eight Trp residues were mutated to phenylalanine (Phe). W62F and W116F both of which are located on the N-terminal ODLA binding domain, exhibited a reduced blue shift upon ODLA binding as compared to wild-type HepI. Additionally, these residues are located on dynamic loops (N-3 and N-7) suggesting that these loops may undergo conformational changes when ODLA binds, leading to a change in local environment of W62 and W116. Interestingly, the W217F mutant (Trp located on the C-terminal domain far from the ODLA binding site) resulted in a complete loss of the blue shift upon substrate binding. Although more experiments are need to fully understand the role of W217, upon ODLA binding, ADPH binding may be altered (ADPH is directly moved to impact W217 conformation), suggesting communication between the two domains.

In addition to fluorescence spectroscopy, circular dichroism (CD) experiments were used to investigate structural changes of HepI [72,73]. CD spectra for HepI demonstrate a characteristic spectra for a protein with primarily $\alpha$ content with a double minimum with peaks at $222 \mathrm{~nm}$ and $211 \mathrm{~nm}$. Interestingly, upon binding of ODLA there is an increase in the intensity of the second minimum at around $211 \mathrm{~nm}$ consistent with a $12 \%$ increases in $\alpha$-helicity (Figure 11A). The location of these conformational changes are unknown, but most likely this is the result of structural changes of disordered loops in HepI [71].

Protein stability was also explored by CD melts experiments (taking CD spectra at varying temperatures) and monitoring unfolding of protein. As can be seen in Figure 11B,C, apo HepI has a $\mathrm{T}_{\mathrm{M}}$ of $40{ }^{\circ} \mathrm{C}$, however upon ODLA binding there is a large increase in stability so that even at $95^{\circ} \mathrm{C}$ the protein is still mostly folded [71]. It was concluded that the formation of HepI.ODLA complex must lead to formation of hydrogen bonds and/or salt bridges (ionic interactions) between ODLA and HepI. Without cyrstalographic evidence showing where ODLA binds, its hard to determine which interactions induce such a stabilization. Examination of the HepI structure reveals that there are many positively charged residues located on dynamic loops of the N-terminal domain (where ODLA 
binds) which could coordinate with negatively charged phosphate and carboxylate moieties of ODLA. High salt reverses some of the HepI.ODLA complex stabilization, suggesting that ionic interactions are essential for HepI-ODLA complex stabilization [71]. In sum, these data strongly support the hypothesis of heptosyltransferases undergoing open to closed transitions.
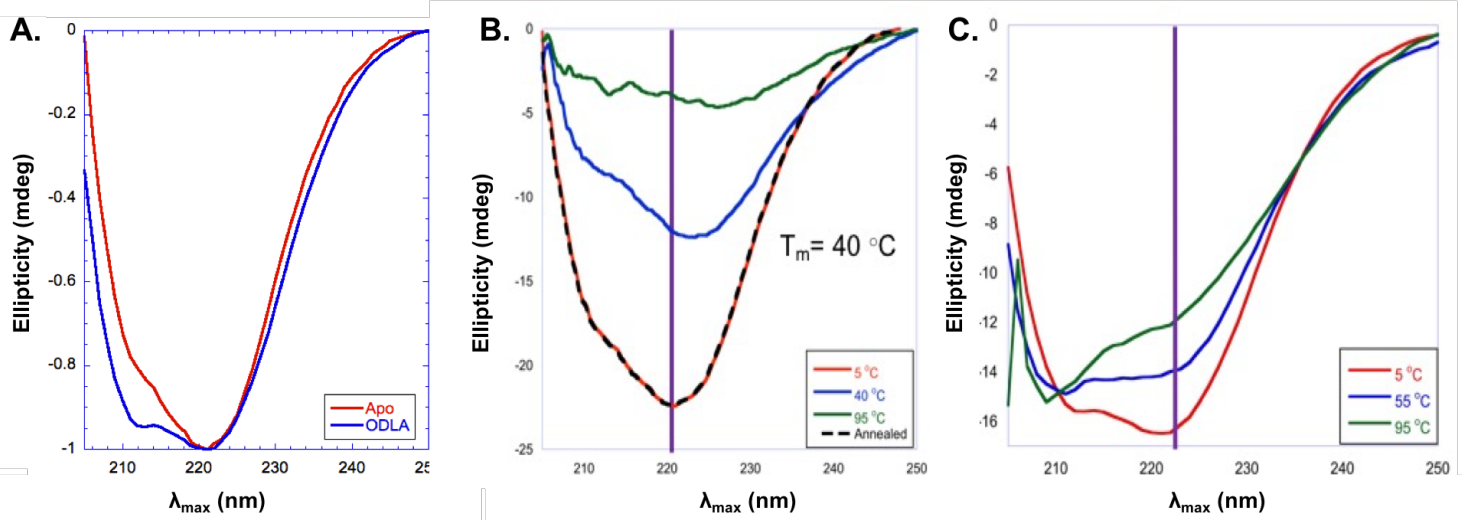

Figure 11. (A) Far-UV circular dichroism (CD) spectra of apo HepI (red), HepI with $100 \mu \mathrm{M}$ ADPH (dark green), and HepI with $100 \mu \mathrm{M}$ ODLA (blue) at $5{ }^{\circ} \mathrm{C}$. Far-UV CD Melt spectra of (B) apo HepI at $5{ }^{\circ} \mathrm{C}$ (red), $40{ }^{\circ} \mathrm{C}$ (blue), $95^{\circ} \mathrm{C}$ (green) and annealed at $5{ }^{\circ} \mathrm{C}$ (black) and (C) HepI with $100 \mu \mathrm{M}$ ODLA $5{ }^{\circ} \mathrm{C}$ (red), $40^{\circ} \mathrm{C}$ (blue) and $95^{\circ} \mathrm{C}$ (green). Purple lines demonstate changes in ellipticity at $222 \mathrm{~nm}$.

\section{Conclusions}

With the growing need for new antibiotics to treat antibiotic resistant (and multi-resistant) bacteria, it is essential for scientists to find new and smarter ways to inhibit bacterial growth. Heptosyltransferases are important for LPS biosynthesis and the resulting resistance. Structurally HepI-IV are very similar and all adopt a GT-B structural fold. HepI can be used as a model for other heptosyltransferases and GT-B enzymes to inform inhibition strategies. Perhaps disruption of GT-B dynamics with small molecules would be an effective new strategy for inhibitor development. Additionally, dynamics disruption could potentially allow for inhibition of multiple targets which undergo similar dynamical changes (with a single drug targeting multiple enzymes). Promising work has been done to understand the function of HepI and aid in designing such an inhibitor. Ultimately, heptosyltransferases provide useful information about the GT-B structural fold and provide a model for novel methods to inhibit many GT-B enzymes.

Author Contributions: J.M.C. and E.A.T. contributed equally to the conception and writing of this paper.

Conflicts of Interest: The authors declare no conflict of interest.

\section{References}

1. Barbier, F.; Luyt, C. Understanding resistance. Intensiv. Care Med. 2016, 42, 2080-2083.

2. Centers for Disease Control and Prevention (CDC). Antibiotic Resistance Threats in the United States, 2013; Technical Report; CDC; U.S. Department of Health and Human Services: Atlanta, GA, USA, 2013. Available online: http://www.cdc.gov/drugresistance/pdf/ar-threats-2013-508.pdf (accessed on 28 September 2017).

3. World Health Organization (WHO). Antibiotic Resistance; Fact Sheet; World Health Organization (WHO), 2016. Available online: http://www.who.int/mediacentre/factsheets/antibiotic-resistance/en/ (accessed on 28 September 2017).

4. Ruiz, N.; Kahne, D.; Silhavy, T.J. Advances in understanding bacterial outer-membrane biogenesis. Nat. Rev. Microbiol. 2006, 4, 57-66.

5. Nikaido, H. Molecular Basis of Bacterial Outer Membrane Permeability Revisited. Microbiol. Mol. Biol. Rev. 2003, 67, 593-656. 
6. Piek, S.; Kahler, C.M. A comparison of the endotoxin biosynthesis and protein oxidation pathways in the biogenesis of the outer membrane of Escerichia coli and Neisseria meningitidis. Front. Cell. Infect. Microbiol. 2012, 2, 162.

7. Raetz, C.; Reynolds, M.C.; Trent, S.M.; Bishop, R.E. Lipid A Modification Systems in Gram-Negative Bacteria. Annu. Rev. Biochem. 2007, 76, 295-329.

8. Schnaitman, C.A.; Klena, J.D. Genetics of Lipopolysaccharide Biosynthesis in Enteric Bacteria. Microbiol. Rev. 1993, 57, 655-682.

9. Raetz, C.R.; Whitfield, C. Lipopolysaccharide endotoxins. Annu. Rev. Biochem. 2002, 71, 635-700.

10. Coleman, W.G.; Leive, L. Two mutations which affect the barrier function of the Escherichia coli K-12 outer membrane. J. Bacteriol. 1979, 139, 899-910.

11. Stenutz, R.; Weintraub, A.; Widmalm, G. The structures of Escherichia coli O-polysaccharide antigens. FEMS Microbiol. Rev. 2006, 30, 382-403.

12. Lerouge, I.; Vanderleyden, J. O-antigen structural variation: Mechanisms and possible roles in animal/ plant-microbe interactions. FEMS Microbiol. Rev. 2002, 26, 17-47.

13. Chatterjee, S.N.; Chaudhuri, K. Lipopolysaccharides of Vibrio cholerae: I. Physical and chemical characterization. Biochim. Biophys. Acta 2003, 1639, 65-79.

14. Caroff, M.; Karibian, D. Structure of bacterial lipopolysaccharides. Carbohydr. Res. 2003, 338, $2341-2347$.

15. Heinrichs, D.E.; Yethon, J.A.; Whitfield, C. Molecular basis for structural diversity in the core regions of the lipopolysaccharides of Escherichia coli and Salmonella enterica. Mol. Microbiol. 1998, 30, 221-232.

16. Raetz, C.R.; Garrett, T.A.; Reynolds, C.M.; Shaw, W.A.; Moore, J.D.; Dale, C.; Smith, J.; Ribeiro, A.A.; Murphy, R.C.; Ulevitch, R.J.; et al. $\mathrm{Kdo}_{2}$-Lipid A of Escherichia coli, a defined endotoxin that activates microphages via TLR-4. J. Lipid Res. 2006, 47, 1097-1111.

17. Whitfield, C.; Trent, M. Biosynthesis and export of bacterial lipopolysaccharides. Annu. Rev. Biochem. 2014, 83, 99-128.

18. Delcour, A.H. Outer membrane permeability and antibiotic resistance. Biochim. Biophys. Acta 2009, 1794, 808-816.

19. Klein, G.; Lindner, B.; Brabetz, W.; Brade, H.; Raina, S. Escherichia coli K-12 Suppressor-free Mutants Lacking Early Glycosyltransferase and Late Acyltransferase: Minimal Lipopolysaccharide Structure and Induction of Envelope Stress Response. J. Biol. Chem. 2009, 284, 15369-15389.

20. Kanipes, M.I.; Holder, L.C.; Corcoran, A.T.; Moran, A.P.; Guerry, P. A Deep-Rough Mutant of Campylobacter jejuni 81-176 Is Noninvasive for Intestinal Epithelial Cells. Infect. Immun. 2004, 72, 2452-2455.

21. Raetz, C.R. Bacterial lipopolysaccharides: A remarkable family of bioactive macroamphiphiles. In Escherichia coli and Salmonella: Cellular and Molecular Biology; Neidhardt, F.C., Curtiss, R., III, Ingraham, J.L., Lin, E.C.C., Low, K.B., Magasanik, B., Reznikoff, W.S., Riley, M., Schaechter, M., Umbarger, H.E., Eds.; American Society for Microbiology: Washington, DC, USA, 1996.

22. Coutinho, P.M.; Deleury, E.; Davies, G.J.; Henrissat, B. An Evolving Hierarchical Family Classification for Glycosyltransferases. J. Mol. Biol. 2003, 328, 307-317.

23. Varki, A.; Cummings, R.; Esko, J.; Freeze, H.; Hart, G.; Marth, J. (Eds) Essentials of Glycobiology; Cold Spring Harbor Laboratory Press: Cold Spring Harbor, NY, USA, 1999; Chapter 17 (Glycosyltransferases); pp. 253-262.

24. Albesa-Jové, D.; Giganti, D.; Jackson, M.; Alzari, P.; Guerin, M. Structure-function relationships of membrane-associated GT-B glycosyltransferases. Glycobiology 2014, 24, 108-124.

25. Lairson, L.; Henrissat, B.; Davies, G.; Withers, S. Glycosyltransferases: Structures, functions, and mechanisms. Annu. Rev. Biochem. 2008, 77, 521-555.

26. Lombard, V.; Golaconda Ramulu, H.; Drula, E.; Coutinho, P.M.; Henrissat, B. The carbohydrate-active enzymes database (CAZy) in 2013. Nucleic Acids Res. 2014, 42, D490-D495.

27. Sinnott, M.L. Catalytic mechanism of enzymic glycosyl transfer. Chem. Rev. 1990, 90, 1171-1202, doi:10.1021/cr00105a006.

28. Charnock, S.J.; Davies, G.J. Structure of the Nucleotide-Diphospho-Sugar Transferase, SpsA from Bacillus subtilis, in Native and Nucleotide-Complexed Forms. Biochemistry 1999, 38, 6380-6385, doi:10.1021/bi990270y.

29. Pak, J.E.; Arnoux, P.; Zhou, S.; Sivarajah, P.; Satkunarajah, M.; Xing, X.; Rini, J.M. X-ray Crystal Structure of Leukocyte Type Core $2 \beta 1,6-N$-Acetylglucosaminyltransferase: Evidencec for a Convergence of Metal Ion-independent Glycosyltransferase Mechanism. J. Biol. Chem. 2006, 281, 26693-26701. 
30. Urresti, S.; Albesa-Jové, D.; Schaeffer, F.; Pham, H.T.; Kaur, D.; Gest, P.; van der Woerd, M.J.; Carreras-González, A.; López-Fernández, S.; Alzari, P.M.; et al. Mechanistic Insights into the Retaining Glucosyl-3-phosphoglycerate Synthase from Mycobacteria. J. Biol. Chem. 2012, 287, 24649-24661.

31. Grizot, S.; Salem, M.; Vongsouthi, V.; Durand, L.; Moreau, F.; Dohi, H.; Vincent, S.; Escaich, S.; Ducruix, A. Structure of the Escherichia coli Heptosyltransferase WaaC: Binary Complexes with ADP and ADP-2-deoxy-2-Fluoro Heptose. J. Mol. Biol. 2006, 363, 383-394.

32. Vrielink, A.; Rüger, W.; Driessen, H.P.; Freemont, P.S. Crystal structure of the DNA modifying enzyme beta-glucosyltransferase in the presence and absence of the substrate uridine diphosphoglucose. EMBO J. 1994, 13, 3413-3422.

33. Vetting, M.W.; Frantom, P.A.; Blanchard, J.S. Structural and Enzymatic Analysis of MshA from Corynebacterium glutamicum: Substrate-assisted Cataylsis. J. Biol. Chem. 2008, 283, 15834-15844.

34. Mulichak, A.M.; Losey, H.C.; Lu, W.; Wawrzak, Z.; Walsh, C.T.; Garavito, R.M. Structure of the TDP-epi-vancosaminyltransferase GtfA from the chloroeremomycin biosynthetic pathway. Proc. Natl. Acad. Sci. USA 2003, 100, 9238-9243.

35. Liu, J.; Mushegian, A. Three monophyletic superfamilies account for the majority of the known glycosyltransferases. Protein Sci. 2003, 12, 1418-1431.

36. Lizak, C.; Gerber, S.; Numao, S.; Aebi, M.; Locher, K.P. X-ray structure of a bacterial oligosaccharyltransferase. Nature 2011, 474, 350-355.

37. Kozmon, S.; Tvaroška, I. Catalytic Mechanism of Glycosyltranferases: Hybrid Quantum Mechanical/Molecular Mechanical Study of the Inverting N-Acetylglucosaminyltransferase I. J. Am. Chem. Soc. 2006, 128, 16921-16927.

38. Taylor Ringia, E.A.; Schramm, V.L. Transition states and inhibitors of the purine nucleoside phosphorylase family. Curr. Top. Med. Chem. 2005, 5, 1237-1258.

39. Rojas-Cervellera, V.; Ardèvol, A.; Boero, M.; Planas, A.; Rovira, C. Formation of a Covalent Glycosyl-Enzyme Species in a Retaining Glycosyltransferase. Chem. Eur. J. 2013, 19, 14018-14023.

40. Ardèvol, A.; Iglesias-Fernández, J.; Rojas-Cervellera, V.; Rovira, C. The reaction mechanism of retaining glycosyltransferases. Biochem. Soc. Trans. 2016, 44, 51-60.

41. Soya, N.; Fang, Y.; Palcic, M.M.; Klassen, J.S. Trapping and characterization of covalent intermediates of mutant retaining glycosyltransferases. Glycobiology 2011, 21, 547-552.

42. Lee, S.S.; Hong, S.Y.; Errey, J.C.; Izumi, A.; Davies, G.J.; Davis, B.G. Mechanistic evidence for a front-side, SNi-type reaction in a retaining glycosyltransferase. Nat. Chem. Biol. 2011, 7, 631-638.

43. Frantom, P.A.; Coward, J.K.; Blanchard, J.S. UDP-(5F)-GlcNAc Acts as a Slow-Binding Inhibitor of MshA, a Retaining Glycosyltransferase. J. Am. Chem. Soc. 2010, 132, 6626-6627.

44. Wang, X.; Quinn, P.J. Lipopolysaccharide: Biosynthetic pathway and structure modification. Prog. Lipid Res. 2010, 49, 97-107.

45. Schrinner, E. Surface Structures of Microorganisms and Their Interactions with the Mammalian Host. In Proceedings of the Eighteenth Workshop Conference, Hoechst, Schloss Ringberg, Germany, 20-23 October 1987; John Wiley \& Sons: Hoboken, NJ, USA, 1988; Volume 18.

46. Zhao, X.; Wenzel, C.Q.; Lam, J.S. Nonradiolabeling Assay for WaaP, an Essential Sugar Kinase Involved in Biosynthesis of Core Lipopolysaccharide of Pseudomonas aeruginosa. Antimicrob. Agents Chemother. 2002, 46, 2035-2037.

47. Knirel, Y.; Anisimov, A. Lipopolysaccharide of Yersinia pestis, the Cause of Plague: Structure, Genetics, Biological Properties. Acta Nat. 2012, 4, 46-58.

48. Reeves, P.P.; Wang, L. Genomic organization of LPS-specific loci. Curr. Top. Microbiol. Immunol. 2002, 264, $109-135$.

49. Robert, X.; Gouet, P. Deciphering key features in protein structures with the new ENDscript server. Nucleic Acids Res. 2014, 42, W320-W324.

50. Larkin, M.; Blackshields, G.; Brown, N.; Chenna, R.; McGettigan, P.; McWilliam, H.; Valentin, F.; Wallace, I.; Wilm, A.; Lopez, R.; et al. Clustal W and Clustal X version 2.0. Bioinformatics 2007, 23, 2947-2948.

51. Mudapaka, J.; Taylor, E.A. Cloning and Characterization of the Escherichia coli Heptosyltransferase III: Exploring Substrate Specificity in Lipopolysaccharide Core Biosynthesis. FEBS Lett. 2015, 589, 1423-1429.

52. Zhang, Y. I-TASSER server for protein 3D structure prediction. BMC Bioinform. 2008, 9, 40.

53. Roy, A.; Kucukural, A.; Zhang, Y. I-TASSER: A unified platform for automated protein structure and function prediction. Nat. Protoc. 2010, 5, 725-738. 
54. Yang, J.; Yan, R.; Roy, A.; Xu, D.; Poisson, J.; Zhang, Y. The I-TASSER Suite: Protein structure and function prediction. Nat. Methods 2015, 12,7-8.

55. Kadrmas, J.L.; Raetz, C.R.H. Enzymatic Synthesis of Lipopolysaccharide in Escherichia coli: Purification and Properties of Heptosyltransferase I. J. Biol. Chem. 1998, 273, 2799-2807.

56. Czyzyk, D.J.; Liu, C.; Taylor, E.A. Lipopolysaccharide Biosynthesis without the Lipids: Recognition Promiscuity of Escherichia coli Heptosyltransferase I. Biochemistry 2011, 50, 10570-10572.

57. Larivière, L.; Gueguen-Chaignon, V.; Moréra, S. Crystal Structures of the T4 Phage $\beta$-Glucosyltransferase and the D100A Mutant in Complex with UDP-glucose: Glucose Binding and Identification of the Catalytic Base for a Direct Displacement Mechanism. J. Mol. Biol. 2003, 330, 1077-1086.

58. Moreau, F.; Desroy, N.; Genevard, J.M.; Vongsouthi, V.; Gerusz, V.; Le Fralliec, G.; Oliveira, C.; Floquet, S.; Denis, A.; Escaich, S.; et al. Discovery of New Gram-negative Antivirulence Drugs: Structure and Properties of Novel E. coli WaaC Inhibitors. Bioorg. Med. Chem. Lett. 2008, 18, 4022-4026.

59. Durka, M.; Buffet, K.; Iehl, J.; Holler, M.; Nierengarten, J.F.; Vincent, S.P. The Inhibition of Liposaccharide Heptosyltransferase WaaC with Multivalent Glycosylated Fullerenes: A New Mode of Glycosyltransferase Inhibition. Chem. Eur. J. 2012, 18, 641-651.

60. Tikad, A.; Fu, H.; Sevrain, C.M.; Laurent, S.; Nierengarten, J.; Vincent, S.P. Mechanistic Insight into Heptosyltransferase Inhibition by using Kdo Multivalent Glycoclusters. Chem. Eur. J. 2016, 22, 13147-13155.

61. Czyzyk, D.J.; Sawant, S.; Ramirez-Mondragon, C.A.; Hingorani, M.M.; Taylor, E.A. Escherichia coli Heptosyltransferase I: Investigation of Protein Dynamics of a GT-B Structural Enzyme. Biochemistry 2013, 52, 5158-5160.

62. Garrity, J.D.; Pauff, J.M.; Crowder, M.W. Probing the Dynamics of a Mobile Loop above the Active Site of L1, a Metallo- $\beta$-lactamase from Stenotrophomonas maltophilia, via Site-directed Mutagenesis and Stopped-flow Fluorescence Spectroscopy. J. Biol. Chem. 2004, 279, 39663-39670.

63. Dumitraşcu, L.; Stănciuc, N.; Bahrim, G.E.; Ciumac, A.; Aprodu, I. pH and heat-dependent behaviour of glucose oxidase down to single molecule level by combined fluorescence spectroscopy and molecular modelling. J. Sci. Food Agric. 2016, 96, 1906-1914.

64. Hogue, C.W.V.; Doublié, S.; Xue, H.; Wong, J.T.; Carter, C.W., Jr.; Szabo, A.G. A Concerted Tryptophanyl-adenylate-dependent Conformational Change in Bacillus subtilis Tryptophanyl-tRNA Synthetase Revealed by the Fluorescence of Trp92. J. Mol. Biol. 1996, 260, 446-466.

65. Lakowicz, J.R. Principles of Fluorescence Spectroscopy; Springer: Berlin, Germany, 2007.

66. Meera, K.B.; Debra, A.K. Fluorescence spectroscopy of soluble E. coli SPase I $\Delta 2-75$ reveals conformational changes in response to ligand binding. Proteins 2014, 82, 596-606.

67. Haiyuan, D.; Ishita, M.; Donald, O. Lipid and Signal Peptide-Induced Conformational Changes within the C-Domain of Escherichia coli SecA Protein. Biochemistry 2001, 40, 1835-1843.

68. Imhof, N.; Kuhn, A.; Gerken, U. Substrate-Dependent Conformational Dynamics of the Escherichia coli Membrane Insertase YidC. Biochemistry 2011, 50, 3229-3239.

69. Wong, C.F.; McCammon, A.J. Dynamics and design of enzymes and inhibitors. J. Am. Chem. Soc. 1986, 108, 3830-3832.

70. Liu, X.; Cao, Y.F.; Ran, R.X.; Dong, P.P.; Gonzalez, F.J.; Wu, X.; Huang, T.; Chen, J.X.; Fu, Z.W.; Li, R.S.; et al. New insights into the risk of phthalates: Inhibition of UDP-glucuronosyltransferases. Chemosphere 2016, 144, 1966-1972.

71. Cote, J.M.; Ramirez-Mondragon, C.A.; Siegel, Z.S.; Czyzyk, D.J.; Gao, J.; Sham, Y.Y.; Mukerji, I.; Taylor, E.A. The Stories Tryptophans Tell: Exploring Protein Dynamics of Heptosyltransferase I from Escherichia coli. Biochemistry 2017, 56, 886-895, doi:10.1021/acs.biochem.6b00850.

72. Zhang, N.; Peng, K.C.; Chen, L.; Puett, D.; Pierce, M. Circular Dichroic Spectroscopy of N-Acetylglucosaminyltransferase V and Its Substrate Interactions. J. Biol. Chem. 1997, 272, 4225-4229.

73. Cavatorta, P.; Sartor, G.; Neyroz, P.; Farruggia, C.; Franzoni, L.; Szabo, A.G.; Spisni, A. Fluorescence and CD studies on the conformation of the gastrin releasing peptide in solution and in the presence of model membranes. Biopolymers 1991, 31, 653-661.

(C) 2017 by the authors. Licensee MDPI, Basel, Switzerland. This article is an open access article distributed under the terms and conditions of the Creative Commons Attribution (CC BY) license (http:/ / creativecommons.org/licenses/by/4.0/). 